\title{
DUMPING SOCIAL NO DIREITO DO TRABALHO.
}

Mayara Souza de Oliveira, Mari Ângela Pelegríni

Universidade do Oeste Paulista - UNOESTE, Curso de Direito, Presidente Prudente, SP. E-mail: mayara unesp@hotmail.com

\section{RESUMO}

O Dumping Social é caracterizado pela omissão dos direitos trabalhistas mínimos, objetivando diminuir os custos de produção, obtendo, assim, um preço final do produto ou serviço inferior ao praticado pelas demais empresas que não adotam essa conduta. Esse comportamento prejudica a economia e lesa diretamente os trabalhadores, além de configurar um crime contra a ordem econômica, pois gera lucros indevidos e dominação de mercado. O objetivo do presente artigo é discorrer sobre o Dumping Social, assunto ainda pouco abordado pela doutrina trabalhista nacional, e a importância do Judiciário no seu combate, tendo em vista a inexistência de legislação que repreenda essa prática nefasta. A metodologia constou de pesquisas bibliográficas, os dados obtidos foram analisados utilizando-se do método hipotético dedutivo. Com a presente pesquisa constatou-se que, em razão da inexistência de legislação específica a postura proativa do Judiciário é uma importante arma no combate ao Dumping Social.

Palavras-Chave: Dumping Social. Ativismo Judicial. Concorrência.

\section{SOCIAL DUMPING IN LABOR LAW.}

\begin{abstract}
The Social Dumping is characterized by the omission of the minimum labor rights, aiming to reduce the production costs, getting, thereby, a final price of the product or service below that charged by the other companies that do not adopt such conduct. This behavior harms the economy and affects the employees directly, as well as configures a crime against the economy order, because it creates undue profits and market domination. The purpose of this article is to expatiate on the Social Dumping, matter yet little addressed by national labor doctrine, and the importance of the judiciary in your combat, considering the absence of legislation to reprove this nefarious practice. The methodology consisted of bibliographic research, the data obtained were analyzed using the hypothetical deductive method. With this research it was found that, due to the absence of specific legislation the proactive stance of the judiciary is an important weapon in the fight against Social Dumping.
\end{abstract}

Keywords: Social Dumping. Judicial activism. Competition. 


\section{INTRODUÇÃO}

O objetivo do empreendedor quando cria uma empresa é o lucro, no entanto, o lucro não pode ser buscado a qualquer preço, exatamente por esse motivo a Constituição Federal prevê limites para atuação empresarial, como respeito à livre concorrência, aos direitos socais, ao meio ambiente e a função social da empresa. Para que uma empresa atinja sua finalidade social ela não deve apenas visar o lucro, o empresário deve ter em mente e se preocupar com as consequências da sua atividade e os reflexos de suas decisões na sociedade. Todavia, algumas empresas utilizamse de manobras ilícitas para obtenção de lucro, não respeitando os limites colocados pela Constituição para o exercício da atividade empresarial, como o desrespeito aos direitos trabalhistas.

O dumping social é caracterizado pela omissão dos direitos mínimos dos trabalhadores, para alcançar um custo de produção inferior, e oferecer preços menores ao mercado. Com a finalidade de obter lucro, empresas migram para países onde os direitos trabalhistas são escassos ou até inexistentes, isso porque os encargos trabalhistas configuram uma parcela considerável do custo de produção, assim a competividade de uma empresa que está livre desses custos é muito maior.

Ao contrário do que se possa imaginar, a prática de dumping social não é um fenômeno verificado apenas no comércio exterior, ao contrário, muitas empresas nacionais não respeitam os direitos dos trabalhadores, essa conduta perpetrada de forma reiterada configura o exercício de dumping. No entanto, em razão da atualidade do tema não há legislação específica que prevê e pune a prática do dumping social na esfera trabalhista, ficando sua punição e repressão a cargo do Judiciário que, de forma proativa, vem condenando e punindo essa conduta.

O escopo deste artigo é abordar o dumping social no Direito do Trabalho e a importância da postura proativa do judiciário no seu combate.

\section{METODOLOGIA}

O artigo foi embasado em pesquisas bibliográficas, leituras, bem como em leis, resoluções e artigos eletrônicos. Os dados foram examinados com a aplicação do método hipotéticodedutivo, isto é, partindo do geral para o particular e as informações coletadas analisadas e confrontadas de forma dialética.

\section{DISCUSSÃO}

Ao Regular a concorrência, o legislador elegeu princípios balizadores que devem ser observados, como a soberania nacional, a propriedade privada, a função social da propriedade, a livre concorrência, a defesa do consumidor, a defesa do meio ambiente, a redução das desigualdades regionais e sociais, a busca do pleno emprego, entre outros. Observa-se que o legislador impôs limites ao exercício das atividades empresariais, sendo livre o seu exercício, desde que pautado nos princípios acima citados.

Um mercado baseado na livre concorrência é aquele em que os agentes econômicos não se utilizam de meios escusos para obter lucro, ou seja, o lucro é obtido com a utilização de alguns instrumentos, tais como, boa administração, investimento em tecnologias, técnicas de produção, treinamento de pessoal e etc. Ocorre que nem sempre a livre concorrência é respeitada, existindo empresas que adotam condutas arbitrárias visando obter lucros maiores e com isso dominar mercados.

Existem várias manobras aptas a lesar a livre concorrência e alcançar lucros de forma arbitrária. Alguns agentes econômicos utilizam-se da manipulação de mercados por meio de cartéis, outros de evasão fiscal e ainda há aqueles que para alcançar ganhos maiores deixam de observar os direitos trabalhistas. Essas manobras atingem de maneira danosa a concorrência, trazendo prejuízos aos concorrentes que não adotam esse tipo de conduta, aos consumidores que 
são atingidos com a exclusão de empresas do mercado e o monopólio em alguns setores, que influenciam nos preços dos produtos, encarecendo-os. No entanto, a não observância dos direitos trabalhistas, além dos danos citados, acarretam danos diretos aos trabalhadores, que são privados de seus direitos mínimos.

A Constituição Federal ao lado das liberdades e direitos fundamentais trata também dos assuntos sociais. Dentro dos direitos sociais estão previstos os direitos trabalhistas, tendo o legislador pátrio estabelecido direitos mínimos aos trabalhadores. Os direitos sociais têm como função assegurar o direito mais caro do nosso ordenamento jurídico, qual seja, a dignidade humana. Os direitos sociais são impostos tanto ao Estado, responsável por implementar políticas públicas de promoção social, como a todos os demais cidadãos nas suas relações intersubjetivas. (SOUTO MAIOR, 2007, p.2).

A Lei 12.529/2011 que trata da prevenção e repressão às infrações contra a ordem econômica dispõe em seu artigo 36, que configura crime contra a ordem econômica, independentemente de culpa, os atos que tenham como finalidade limitar ou prejudicar a livre concorrência e a livre iniciativa, dominar mercado relevante e aumentar arbitrariamente os lucros. (CONGRESSO NACIONAL, 2011, p. 1).

Ao suprimir os direitos trabalhistas de seus empregados, o agente econômico consegue um preço final do produto inferior ao oferecido pelas empresas do mesmo ramo que respeitam esses direitos, essa conduta afeta diretamente a concorrência e os personagens nela inseridos, dessa forma, além de atentar contra os direitos trabalhistas, o empregador que adota esse tipo de conduta comete crime contra a ordem econômica, pois com isso, aumenta arbitrariamente seus lucros, podendo até mesmo dominar o mercado daquele produto ou serviço.

O desenvolvimento da atividade econômica deve estar ligado à promoção da dignidade humana e a busca da justiça social. Isso, no entanto, na maioria das vezes não ocorre, ao contrário, muitas empresas consideram o trabalho humano mera mercadoria, sendo indispensável a atuação positiva do Poder Judiciário para que sejam acatadas as ordens constitucionais (FERNANDEZ, 2014, p. 19).

Vivemos em uma sociedade capitalista. Justamente por este motivo a nossa atual constituição reservou capítulos específicos para tratar dos direitos sociais. Neles se situam os direitos trabalhistas e os reservados à preservação da ordem econômica. Esse cuidado do legislador em proteger a propriedade privada e o livre empreendedorismo, sem deixar de lado os direitos dos trabalhados, demonstra que a interpretação dessas regras não pode ser realizada de uma maneira dissociada. Todo trabalhador tem direito de ver reconhecida a importância de seu trabalho para o desenvolvimento nacional, tendo ainda direito a condições dignas de trabalho e garantia de seus direitos. O tratamento diferenciado entre os empregados, a não observância de direitos como os relacionados à segurança do trabalho, jornada de trabalho, salário mínimo ou piso da categoria, férias, verbas trabalhistas entre outros, são exemplos da desvalorização do trabalho humano e da visão que o labor humano não passa de um fator de produção, utilizado para obtenção de lucro, sem dispensar o devido respeito aos trabalhadores (FERNANDEZ, 2014, p. 55).

Da leitura dos incisos do artigo $7^{\circ}$, da Constituição federal, verifica-se que o constituinte dedicou uma atenção especial às normas de proteção ao trabalho. Todavia, a realidade fática indica que os preceitos constitucionais não são acatados pela maioria dos empregadores que, sob o argumento de prosperidade empresarial suprimem, deliberadamente, os direitos trabalhistas. Com a desobediência dos direitos do trabalhador, os custos de produção diminuem o que consequentemente eleva o lucro, essa manobra a qual algumas empresas lançam mão é denominada de Dumping Social.

O dumping social caracteriza uma forma de concorrência desleal, onde são comercializados produtos e serviços a preços inferiores ao ordinariamente praticado no mercado, "obtidos 
mediante a reiterada utilização de mão de obra em condições inadequadas a padrões laborais mínimos, gerando danos sociais" (FERNANDEZ, 2014, p.85).

Na definição de José Augusto Rodrigues Pinto (2011, p.7), dumping social "corresponde à deterioração do contrato individual de emprego em benefício do lucro do empregador com sacrifício das obrigações e encargos sociais tutelares do empregado".

A vulnerabilidade do empregado e os altos custos dos encargos trabalhistas são fatores que encorajam a prática do dumping social.

Em relação à legislação acerca do dumping social, salienta Aline de Farias Araújo (2011, p. 22) que a legislação trabalhista não prevê esse tipo de conduta, não constituindo objeto do Direito do Trabalho, estando o dumping tratado pelo Direito Econômico, sendo tratado atualmente pelo Código Antidumping da Organização Mundial de Comércio. No entanto, o aumento na adoção dessa prática abusiva pelas empresas, com objetivo de obtenção de vantagens concorrenciais e as consequências prejudicais acarretadas pelo dumping social aos trabalhadores e a toda sociedade, vem aumentando a preocupação dos estudiosos do Direito do Trabalho em relação a essa prática abusiva. Souto Maior salienta que o Direito Social é um valor essencial previsto na nossa Constituição, "essa noção axiológica faz com que o Direito Social, como os Direitos Humanos em geral, tenha incidência na realidade independente de uma lei que o prescreva expressamente e, se necessário, até contrariando alguma lei existente" (SOUTO MAIOR, 2007, p.4).

Em decorrência da inexistência de previsão do dumping social no Direito do Trabalho, foi aprovada, durante a $1^{\text {a }}$ Jornada de Direito Material e Processual do Trabalho, realizada no ano de 2007, em Brasília, o Enunciado 4 que prevê a imposição de indenização suplementar, caso configurado o dumping social. O referido enunciado prevê que essa conduta desconsidera propositalmente o Estado social e o modelo capitalista, caracterizando exercício abusivo do direito, já que afronta os direitos econômicos e sociais, devendo o agressor costumaz ser condenado ao pagamento de indenização suplementar. Também há jurisprudência admitindo a aplicação de indenização suplementar por caracterização de dumping social, como a decisão proferida pelo TRT da 4a Região, onde a reclamada foi condenada ao pagamento de indenização a título de dumping social, em razão da reiterada desobediência e precarização dos direitos dos trabalhados que ficou caracterizado nos autos (TRT 4a REGIÃO, 2011, p.1).

O dumping social além das consequências nefastas causadas aos trabalhadores configura também um dano transindividual, extrapolando as esferas individuais e afetando uma quantidade indeterminada de pessoas, assim a mera reparação individual não é suficiente para ressarcir integralmente os malefícios decorrentes dessa conduta. O contrato de emprego supera o limite das relações privadas, pois constitui uma relação jurídica complexa, sendo superior a simples compra e venda de mão de obra, pois está relacionado, inseparavelmente, com os princípios da solidariedade, da dignidade humana e da responsabilidade social. Dessa forma, as agressões aos direitos trabalhistas, em decorrência da complexidade das relações de emprego, atinge uma quantidade indeterminada de pessoas, haja vista que o dumping social tem como um de seus resultados a obtenção de vantagem na concorrência frente aos empregadores que não se valem desses meios, implicando em danos a esses empresários que são punidos até mesmo com a extinção de suas empresas por não conseguirem acompanhar os preços praticados pelas empresas infratoras.

Diante da verificação, cada dia mais frequente, de litigantes contumazes na Justiça do Trabalho, pela inobservância reiterada dos direitos trabalhistas, o Judiciário mostra-se indispensável na repressão ao dumping social e à precarização dos direitos dos trabalhadores. Pois, quando a conduta do empregador caracteriza um dano social, além de infringir as leis trabalhistas este comete um ato ilícito, como preveem os artigos 186 e 187 do Código Civil. Dessa forma, a conduta do autor do dano ultrapassa o mero inadimplemento contratual, devendo o 
valor da indenização, na forma do artigo 944 do Código Civil, ser mensurado pela extensão do dano, considerando-se seus aspectos individuais e sociais (SOUTO MAIOR, 2007, p.6).

Tendo em vista o fato de esse dano ultrapassar a esfera individual, a condenação ao pagamento apenas dos direitos trabalhistas sonegados não são suficientes para reparar integralmente o dano. Não obstante seja o trabalhador o prejudicado de forma direta, o dumping social lesa uma quantidade indefinida de pessoas, acarretando lesão à concorrência, aos consumidores e até aos trabalhadores de toda uma região, pois os demais empregadores se veem obrigados a adotar a mesma conduta para conseguirem manter seus produtos e serviços no mercado. Em decorrência desse dano coletivo ocasionado pelo dumping social, alguns autores, como Jorge Souto Maior (2007, p. 7), entendem cabível a aplicação do fluid recovery, também denominado de ressarcimento fluído ou global, onde o juiz condena o réu também pelos danos coletivos advindos de sua conduta, mesmo na hipótese de ação individual, ou seja, fora do âmbito da ação coletiva. A aplicação do fluid recovery ocasiona a condenação do reclamado ao pagamento de indenização suplementar em decorrência do dano social evidenciado no processo, mesmo que não haja pedido expresso neste sentido.

São atraentes as teses que defendem a aplicação do fluid recovery para reparação integral dos danos causados pela prática de dumping social, no entanto, não é pacífica sua aplicação, existindo até mesmo posição do TST em sentido contrário, tendo o Tribunal entendido que a condenação em quantidade superior ou em objeto distinto do que foi pleiteado configura julgamento extra petita, extrapolando os limites impostos pela lide, não sendo cabível a indenização suplementar por dano social, sem que essa tenha sido requerida pela parte (TST, 2012, p.1).

A aplicação do fluid recovery evidencia a nova postura proativa do Poder Judiciário. Atualmente o ativismo judicial transformou-se em uma ferramenta importantíssima para alcançar a Justiça. "A ideia de ativismo judicial está associada a uma participação mais ampla e intensa do Judiciário na concretização dos valores e fins constitucionais, com maior interferência no espaço de atuação dos outros dois Poderes". Com a aplicação do ativismo, o Poder Judiciário é capaz de atender demandas da sociedade que pela atualidade do tema não se encontram reguladas pelo Poder Legislativo, no entanto, não se trata de regra absoluta, pois é preciso levar em consideração limites como os princípios da proporcionalidade e da razoabilidade (TEIXEIRA, FRANKLIN, 2014, p. 118).

Não obstante a decisão do Colendo Tribunal Superior do Trabalho, a imposição de indenização suplementar de ofício, em decorrência da configuração de dano social, configura uma forma de combate ao dumping social, tendo em vista que a simples condenação ao pagamento dos direitos trabalhistas sonegados não tem o condão de reprimir esta conduta e acaba até mesmo incentivando o seu exercício, pois caso algo ocorra errado, o máximo que acontecerá será o pagamento dos danos individuais suportados pelo trabalhador, o que torna a conduta vantajosa. Assim a postura proativa do Judiciário tem dupla função, pois pune a realização do dumping social e funciona como pena pedagógica, posto que desincentiva a adoção de tais métodos para obter lucro.

\section{CONCLUSÃO}

Este breve artigo revela a importância do Judiciário materializado no que se convencionou chamar de ativismo judicial, postura proativa adotada pelo Judiciário, frente a questões que ainda não foram objeto de regulamentação pelo Legislativo, indispensável na atualidade no tratamento de questões conflitantes e de grande expressão para a sociedade em geral, e dos trabalhadores em particular, como é o caso do dumping social, já que ainda não regulamentados por lei tais fenômenos. 
A condenação de empresas que o praticam depende hoje de uma postura proativa da magistratura, na louvável tentativa de preenchimento da prejudicial lacuna existe no ordenamento jurídico pátrio a respeito do tema.

Sem embargo desta lamentável inexistência de motivação, pelo menos a curto prazo, de uma efetiva prioridade legislativa, mormente diante da crise política instalada no parlamento, é certo que, ainda que engatinhando, condenações que alertem ou impeçam essa odiosa prática, dependem muito do papel do Ministério Público do Trabalho, como o grande provocador do Judiciário, na defesa dos interesses difusos e coletivos ou individuais homogêneos da coletividade atingida. Uma coisa é certa: apesar de se ter notícia de poucas condenações expressivas, elas já serviram de alerta para empresas violadoras dos direitos humanos, ressaltando a necessidade de regulamentação em lei que, é o que se espera, há de vir.

\section{REFERÊNCIAS}

ARAÚJO, A. F. A necessária repressão da justiça do trabalho aos casos de dumping social. Revista da ESMAT 13, João Pessoa, ano 4, n. 4, p. 18 a 36, out. 2011. Disponível em: <http://goo.gl/QNpTdj> Acesso em: 18 jul. 2016.

BRASIL. C. N. Lei no 12.529, de 30 de novembro de 2011. Estrutura o S.B.D. C; dispõe sobre a prevenção e repressão às infrações contra a ordem econômica (...). DOU, Brasília, DF, 01 dez. 2011. Disponível em: < http://goo.gl/rZvtLP >. Acesso em: 30 jun. 2016.

BRASIL. Enunciado 4. 1a Jornada de Direito Material e Processual do Trabalho, realizada no ano de 2007, em Brasília. Disponível em: <http://goo.gl/xRYZnE>. Acesso em: 30 jun. 2016.

BRASIL. TRT (4. Região). RO n0131000- 63.2009.5.04.0005. Recorrentes: CPM Braxis S.A. E Milton N. de O. Recorridos: os mesmos. Relator: Ricardo C. F. Porto Alegre, 08 junho de 2011. Disponível em: <http://trt-4.jusbrasil.com.br/jurisprudencia/19573258/recurso-ordinario-ro1310006320095040005-rs-0131000-6320095040005>. Acesso em: 30 jun. 2016.

BRASIL. TST. RR n 78200-58.2009.5.04.0005. Recorrente: Atento Brasil S.A. e Recorridas: Alessandra D. B. Relator: Ministro Ives G.M. F.. Brasília, 14 de novembro de 2012. Disponível em: <http://www.tst.jus.br/consulta-unificada>. Acesso em: 18 jul. 2016.

FERNANDEZ, L.. Dumping social. São Paulo: Saraiva, 2014.

SOUTO MAIOR, J. L.. O Dano Social e Sua Reparação. 2007. Disponível em: <http://tpmagister.lex.com.br/lexnet/lexnet.dll/Dout/4d3?f=templates\&fn=documentframe.htm\&2.0>. Acesso em: 30 jun. 2016.

PINTO, J. A. R. Dumping social ou delinquência patronal na relação de emprego?. Revista do

TST, Brasília, v. 77, n. 3, p. 136-153, jul./set. 2011. Disponível em:

<http://www.tst.jus.br/documents/1295387/2684887/Dumping+Social+ou+delinqu\%C3\%AAncia+ patronal+na+rela\%C3\%A7\%C3\%A3o+de+emprego>. Acesso em: 30 jun. 2016.

TEIXEIRA, C. S. N. G.; FRANKLIN, G.. O Papel do Juiz Ativo no Combate ao Dano Social na Justiça do Trabalho. 2014. Disponível em:

$<$ http://periodicos.pucminas.br/index.php/sinapsemultipla/article/download/6853/7488>. Acesso em: 18 jul. 2016. 